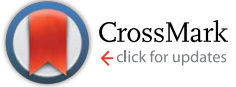

Cite this: RSC Adv., 2015, 5, 6893

Received 6th November 2014 Accepted 15th December 2014

DOI: $10.1039 / c 4 r a 14007 a$

www.rsc.org/advances

\section{Aging of a $\mathrm{Pt} / \mathrm{Al}_{2} \mathrm{O}_{3}$ exhaust gas catalyst monitored by quasi in situ X-ray micro computed tomography $\dagger$}

\author{
Georg Hofmann, ${ }^{a}$ Amélie Rochet, ${ }^{a}$ Elen Ogel, ${ }^{a}$ Maria Casapu, ${ }^{a}$ Stephan Ritter, ${ }^{b}$ \\ Malte Ogurreckc and Jan-Dierk Grunwaldt*a
}

Catalyst aging effects were analyzed using X-ray absorption micro-computed tomography in combination with conventional characterization methods on various length scales ranging from $\mathrm{nm}$ to $\mu \mathrm{m}$ to gain insight into deactivation mechanisms. For this purpose, a $4 \mathrm{wt} \% \mathrm{Pt} / \mathrm{Al}_{2} \mathrm{O}_{3}$ model exhaust gas catalyst was coated on a cordierite honeycomb and subjected to sequential thermal aging in static air at $950{ }^{\circ} \mathrm{C}$ for $4,8,12$ and 24 hours. The aging was followed on the one hand by traditional methods, i.e. CO-oxidation activity, scanning and transmission electron microscopy (SEM, TEM), and X-ray diffraction (XRD). On the other hand, all intermediate aging steps were captured by $\mathrm{X}$-ray absorption micro-computed tomography $(\mu-\mathrm{CT})$ with $1.27 \mu \mathrm{m}$ voxel size using a quasi in situ approach as complementary tool. The $\mu$-CT data allowed comparing exactly the same position after each treatment using a special alignment procedure during data analysis which took into account that the sample was remounted on the sample holder. A growth of the initially nanometer-sized Pt particles into larger crystals as well as its agglomeration was found, preferentially in voids between support grains. Sintering occurred especially around the larger particles, which is in line with the Ostwald ripening mechanism reported for this system on a nanometer scale. The distribution of chemical elements in an embedded and mechanically cross-sectioned honeycomb was additionally mapped by an electron probe micro analyzer (EPMA), which in agreement to the $\mu$-CT results shows no diffusion of Pt into the cordierite. Together with studies on the nanometer scale, these results allow a more thorough multi-scale modeling of exhaust gas catalysts, especially also during aging.

\section{Introduction}

Exhaust gas after treatment is one of the major topics in catalysis, ${ }^{1-3}$ especially, considering that more than 500 million cars are equipped with catalytic converters. Apart from the understanding and development based on characterization on a molecular scale, ${ }^{4-6}$ the design of automotive catalysts at the mesoscopic and macroscopic level is very important to improve their efficiency and durability. ${ }^{4,7,8}$ Typically, the active part of the catalyst, e.g. noble metal particles on alumina for diesel oxidation or three way catalysts, are deposited on structured supports (monoliths). ${ }^{1,2,9}$ The monolithic structures, being composed of several channels separated by thin walls, offer engineering advantages like (i) high open frontal area and thus low pressure

${ }^{a}$ Institute for Chemical Technology and Polymer Chemistry, Karlsruhe Institute of Technology (KIT), D-76131 Karlsruhe, Germany. E-mail: grunwaldt@kit.edu

${ }^{b}$ Institute of Structural Physics, Technical University Dresden (TUD), D-01062 Dresden, Germany

'Institute of Materials Research, Helmholtz-Zentrum Geesthacht (HZG), D-21502 Geesthacht, Germany

$\dagger$ Electronic supplementary information (ESI) available. See DOI: 10.1039/c4ra14007a drop, (ii) high mechanical strength with low thermal expansion and advanced thermal stability, (iii) large geometric surface area for deposition of catalytically active material, and (iv) high conversion efficiency if the layers are designed well, i.e. as a sufficiently thin and porous layer or even two layers to minimize pore diffusion effects. ${ }^{\mathbf{1 0}}$

For automotive applications, the catalytic functionality is, for example, provided by platinum supported on aluminum oxide $\left(\mathrm{Pt} / \mathrm{Al}_{2} \mathrm{O}_{3}\right)$, which is coated on the channel walls. Unfortunately, and common to almost all catalyst systems, a decrease of catalytic activity depending on the conditions and total operation time is observed. For exhaust gas catalysts, apart from poisoning, especially thermal deactivation caused by sintering of active sites is a major problem. ${ }^{\mathbf{1 1 , 1 2}}$ Environmental transmission electron microscopy (ETEM) at elevated temperatures in gas atmosphere was recently able to shed light on the fundamental mechanisms and kinetics ${ }^{6,13,14}$ and to reveal the influence of sintering of $\mathrm{Pt}$ particles under oxidizing conditions. ${ }^{15-17}$ The effects of temperature, gas composition and aging time on the catalytic activity has traditionally been studied by catalytic tests, e.g. CO oxidation, on lab and vehicle aged samples ${ }^{18,19}$ in conjunction with complementary techniques like X-ray diffraction (XRD) or 
scanning electron microscopy (SEM). However, not only the changes on a micro but also the macroscale (change of porosity, change of washcoat layer, etc.) have a strong influence. ${ }^{20}$ Difficulties arise in the preparation and deposition of active materials, namely to achieve uniform, reproducible, and well-adhering coatings. Non-uniform coatings will not fully utilize the precious metals included in the deposited catalyst layer. Large variations in coating reproducibility may decrease the overall system performance and complicate systematic sample comparison. Similarly, a loss of material due to poor adherence will reduce system stability and lower overall performance. ${ }^{21}$ These challenges can be overcome during the catalyst preparation by a careful choice of methods and process parameters as reviewed and discussed in literature. ${ }^{22}$

Hence, recently new methods have been developed to capture structural properties of the catalysts across length and time scales. ${ }^{\mathbf{8} 23}$ Although the importance of in situ studies to understand catalysis is well known, ${ }^{24}$ most conventional characterization methods used to study catalyst deactivation are still conducted post mortem on catalyst samples. Some, especially when analyzing honeycombs by electron microscopy, ${ }^{25}$ may even require sample destruction, e.g. scratching off powders or embedding of material, impeding further complementary studies or further treatments on the same sample. Furthermore, this hampers to assign certain features to their origin in the sample. Additionally, it is always questionable how representative the sample under investigation is, e.g., if using focused ion beam scanning electron microscopy (FIB-SEM). ${ }^{\mathbf{1 , 4}}$ In contrast to these methods, X-ray absorption micro-computed tomography $(\mu-\mathrm{CT})$ can be used in a nondestructive way ${ }^{\mathbf{2 6 , 2 7}}$ as was first demonstrated for sintering of glass powders with $150 \mu \mathrm{m}$ grains using ex situ treatments. ${ }^{28}$ Moreover, X-ray tomography in fluorescence and diffraction mode was used to investigate coated foams ${ }^{29}$ and combined with multiple electron microscopy tomography techniques to study sample porosity across several length scales. ${ }^{30}$ More applications and perspectives have been recently reviewed with respect to energy-related materials ${ }^{31}$ and quantitative $\mathrm{X}$ ray tomography. ${ }^{32}$

In the present study we used quasi in situ X-ray absorption tomography to quantitatively follow the sintering caused by several consecutive ex situ thermal treatments at $950{ }^{\circ} \mathrm{C}$ on a complete single honeycomb channel extracted from a model exhaust gas catalyst with $4 \mathrm{wt} \% \mathrm{Pt} / \mathrm{Al}_{2} \mathrm{O}_{3}$. This allows us for the first time in a non-destructive way to acquire and inspect the interior and the washcoat of a full honeycomb channel. The available field of view captures a sample of $1.2 \times 1.2 \times 1.0 \mathrm{~mm}$ $(x, y, z)$ in three dimensions. Sequentially acquired tomographic data, obtained after thermal treatments, are used to visualize and analyze changes between different aging steps revealing changes on micrometer scale. In addition, the same samples were analyzed by TEM, SEM, electron probe micro analyzer (EPMA), and X-ray diffraction (XRD) to monitor in a complementary manner the sintering on an atomic scale. Finally, CO oxidation was used as a model reaction to show the effects on the catalytic activity.

\section{Sample preparation, aging treatments and characterization methods}

\subsection{Catalyst preparation}

The sample was prepared by incipient wetness impregnation of $5 \mathrm{~h}$ at $700{ }^{\circ} \mathrm{C}$ calcined $\gamma-\mathrm{Al}_{2} \mathrm{O}_{3}\left(165 \mathrm{~m}^{2} \mathrm{~g}^{-1}\right.$, SASOL $)$ with an aqueous solution of hexachloroplatinic acid (Sigma-Aldrich, $c f$. ref. 33) to obtain $4 \mathrm{wt} \%$ Pt loading with respect to the used $\gamma$ $\mathrm{Al}_{2} \mathrm{O}_{3}$ support. A slightly higher loading is used here to optimize imaging contrast in this first study. The resulting $4 \mathrm{wt} \% \mathrm{Pt} / \gamma$ $\mathrm{Al}_{2} \mathrm{O}_{3}$ powder was dried for $12 \mathrm{~h}$ at $80{ }^{\circ} \mathrm{C}$ and calcined at $500{ }^{\circ} \mathrm{C}$ for $2 \mathrm{~h}$ in static air. Cordierite monoliths with 400 channels per square inch (cpsi) were used from which cylindrical samples of approximately $21 \mathrm{~mm}$ diameter, $25 \mathrm{~mm}$ length, and a typical weight of $3.4 \mathrm{~g}$ were obtained by drilling them out of larger ones. They were coated with about $1.2 \mathrm{~g}$ of aqueous slurry containing the catalyst powder and a commercial colloidal silica binder (Ludox AS-40, 10\% of the catalyst mass) resulting in a Pt loading of $160 \mathrm{~g} \mathrm{ft}^{-3}$. After calcination in air at $550{ }^{\circ} \mathrm{C}$ for $5 \mathrm{~h}$ the samples were conditioned for $4 \mathrm{~h}$ at $400{ }^{\circ} \mathrm{C}$ in $5 \mathrm{vol} \% \mathrm{H}_{2} / \mathrm{N}_{2}$.

\subsection{Aging treatments}

In a recent study we followed aging effects across several temperature steps ${ }^{27}$ and found $950{ }^{\circ} \mathrm{C}$ to cause the highest impact on the catalyst layer (crack formation, sintering). Consequently, here we conducted isothermal aging at $950{ }^{\circ} \mathrm{C}$ in a static air furnace for $4,8,12$, and $24 \mathrm{~h}$ to provoke formation of pronounced features on the same sample and observe the effect of aging time. In order to avoid sample damage due to too rapid temperature changes, a heating ramp of $20 \mathrm{~K} \mathrm{~min}^{-1}$ was used. Since the composition of aging atmosphere is known to significantly influence the aging process, additional aging of a fresh sample was performed in a plug-flow reactor using a continuous flow of $2 \mathrm{~L} \mathrm{~min}^{-1} 10$ vol\% $\mathrm{H}_{2} \mathrm{O}$ /air.

\subsection{Characterization methods}

X-ray tomography. X-ray absorption micro computed tomography ( $\mu$-CT) is a well-known technique ${ }^{34}$ that has been recently established at synchrotron radiation sources to improve the resolution and yields the spatially resolved sample absorption by a numerical reconstruction from a series of projected X-ray transmission images of the sample under several rotation angles. Although recent laboratory CTs offer voxels sizes comparable with synchrotron CT beamlines, synchrotron light was exploited in this study. While the source of a laboratory CT generates a cone beam of polychromatic X-rays, synchrotron sources can produce parallel monochromatic Xrays with several orders of magnitude higher intensity. The latter reduces scan time and improves image statistics tremendously. Additionally, no beam hardening occurs with monochromatic X-rays which greatly enhances the ability to differentiate between materials with only minor variations in their attenuation coefficient and which furthermore allows a more quantitative analysis of the attenuation values. The 
parallel beam allows equally good reconstructions for all parts of the projected image. ${ }^{35}$ As we aim for quantitative quasi in situ tomography $^{32}$ of $\mathrm{Pt}$ sintering at highest resolution, both spatially and in material density, we make use of a dedicated tomography beamline hosted at a third generation synchrotron light source.

The experiments were conducted at the "Imaging Beamline (IBL)" P05 at PETRA III (Hamburg, D). ${ }^{36}$ X-ray photons are produced by an undulator and passed through a $\mathrm{Si}(111)$ double crystal monochromator, selecting a photon energy of $18 \mathrm{keV}$. By installing a stack of rotating paper discs in the beam path any coherence was removed from the parallel beam. The sample was scanned in 1200 steps of $0.15^{\circ}$ over a $180^{\circ}$ rotation, taking several dark fields before each measurement and flat fields continuously during the acquisition. To maintain optimal illumination of the sample, the beam position was controlled by a feedback loop and the synchrotron current was used for normalization purposes. A $300 \mu \mathrm{m}$ thick $\mathrm{CdWO}_{4}$ scintillator was used to convert transmitted X-rays to visible light, which was optically magnified by a factor of 10 using an optical microscope and captured in $400 \mathrm{~ms}$ exposure time by a CCD camera (SciCam SC09000M, EHD imaging) with $1.27 \mu \mathrm{m}$ effective pixel size. Reconstructions using filtered back projection were performed without additional binning, resulting in voxel sizes of $1.27 \mu \mathrm{m}$. The data was analyzed and visualized by Avizo Fire 8.1 (FEI), ${ }^{37}$ Python packages NumPy ${ }^{38}$ and matplotlib, ${ }^{39}$ and Fiji. ${ }^{40}$

For thermal treatment, the samples were unmounted from the tomographic setup and sample holder to avoid damage and afterwards reinstalled. This unavoidably changed sample position and orientation. Consequently, the different raw digital volumes are slightly misaligned and cannot be directly compared voxel-by-voxel. To obtain matching volumes we exploit the characteristic pore structure of the temperature stable cordierite walls to manually pre-align the model volume to the reference volume and in a second step to optimize it by using the registration module of Avizo Fire. The determined transformation is applied to the model volume using Lanczos resampling to the coordinate system of the reference volume, which results in two identically sized volumes. These can be compared voxel-by-voxel and thus enable further analysis and visualization ( $c f$. ref. 27).

Electron microscopy techniques. Transmission electron microscopy (TEM) was carried out using a FEI Titan 80-300 aberration corrected microscope (Karlsruhe Nano Micro Facility, KIT). For this purpose, washcoat samples were collected by scratching off the $\mathrm{Pt} / \mathrm{Al}_{2} \mathrm{O}_{3}$ washcoat from the honeycomb and depositing it on carbon coated $\mathrm{Cu}$ TEM grids.

To gain an impression on sub-micron scale particle sizes, SEM was used. Images were taken using a LEO 1530 Gemini microscope equipped with a Schottky-type field-emission electron source (Laboratory for Electron Microscopy, KIT). Sample fragments for inspection were obtained by manually cutting parts out of the coated honeycomb channel, yielding flat, still coated wall segments. Suitable fragments were glued to the sample holder with conductive silver epoxy and additionally carbon coated to avoid charging effects.
An electron probe micro analyzer (EPMA) was used to elucidate Pt distribution and create elemental mappings across the washcoat and cordierite. A JEOL JXA-8530F field emission electron probe micro analyzer (Institute for Micro Process Engineering, KIT) was operated at $U=25 \mathrm{kV}, I=20 \mathrm{nA}, d_{\text {well }}=$ $20 \mathrm{~ms}$. To this end, a honeycomb channel was embedded in epoxy resin after the tomography experiments, cross sectioned, polished, and finally coated with carbon to prevent charging.

Catalytic test. Light-off curves for the fresh and aged samples were measured at $5 \mathrm{~K} \mathrm{~min}^{-1}$ heating ramps from 60 to $200{ }^{\circ} \mathrm{C}$ on $2.1 \times 2.5 \mathrm{~cm}(d \times h)$ honeycomb cylinders mounted inside a quartz glass reactor tube. Thermocouples (type K) were positioned at approx. $1 \mathrm{~cm}$ to the catalyst bed up and downstream. The typical gas composition was $1000 \mathrm{ppm} \mathrm{CO}$ and 10 vol\% $\mathrm{O}_{2}$ in $\mathrm{N}_{2}$ at a gas hour space velocity (GHSV) of $30000 \mathrm{~h}^{-1}$, which was adjusted by mass flow controllers (Bronkhorst High-Tech BV) and continuously measured on-line by an FT-IR spectrometer (Multigas AnalyzerTM, MKS Instruments).

$\mathrm{X}$-ray diffraction. The powder $\mathrm{X}$-ray diffraction patterns were recorded from uncoated fresh and aged $\mathrm{Pt} / \mathrm{Al}_{2} \mathrm{O}_{3}$ powders to provide sufficient amounts of sample material and avoid impurities by cordierite, using a Bruker D8 Advance X-ray diffractometer (ITCP, KIT) with $\mathrm{Cu}$ anode and Ni-filter operated at $35 \mathrm{kV}$ and $45 \mathrm{~mA}$. A variable slit setting was used to maintain a constant irradiated sample area over the scanned $2 \theta$ range from 25 to 85 degrees covered in steps of 0.0164 degree. The average Pt crystallite size was estimated by applying the Scherrer equation $\tau=\frac{K \lambda}{\beta \cos \theta}$ with $K=0.9$ and $\lambda=1.5418 \AA$ and fitting the Pt diffraction peaks by a Gaussian function. ${ }^{41}$

\section{Complementary $\mathrm{Pt} / \mathrm{Al}_{2} \mathrm{O}_{3}$ catalyst characterization}

\subsection{CO oxidation}

CO oxidation was used as model reaction for studying the effect of the applied aging conditions on the catalytic performance. The influence of the treatment temperature, time, and gas atmosphere on the thermal deactivation of supported $\mathrm{Pt} / \mathrm{Al}_{2} \mathrm{O}_{3}$ catalysts has been frequently reported in literature ${ }^{42}$ also for similar systems. ${ }^{43}$ A decrease of the washcoat surface area and the increase of the noble metal particle size due to sintering are reported with increasing temperature and exposure time. Already at $600{ }^{\circ} \mathrm{C}$ the sintering process starts ${ }^{44}$ and for Pt it seems to be accelerated especially by oxidizing environments. ${ }^{15,45}$ Therefore, aging in static air, similar to the conditions during the synchrotron radiation experiments, has been tested in addition to aging under more realistic conditions using 10 vol\% water vapor in the gas stream.

The fresh catalysts used in this study feature highly dispersed Pt nanoparticles with a narrow particle size distribution characterized by a mean particle size below $2 \mathrm{~nm} .{ }^{27}$ This was reflected in the $\mathrm{CO}$ oxidation activity which corresponded to a light-off temperature of about $120^{\circ} \mathrm{C}$ ( $c f$. Fig. 1).

After $4 \mathrm{~h}$ of aging at $950{ }^{\circ} \mathrm{C}$ a pronounced shift in the light-off temperature from $120{ }^{\circ} \mathrm{C}$ to $162{ }^{\circ} \mathrm{C}$ (in static air) and to $154{ }^{\circ} \mathrm{C}$ 


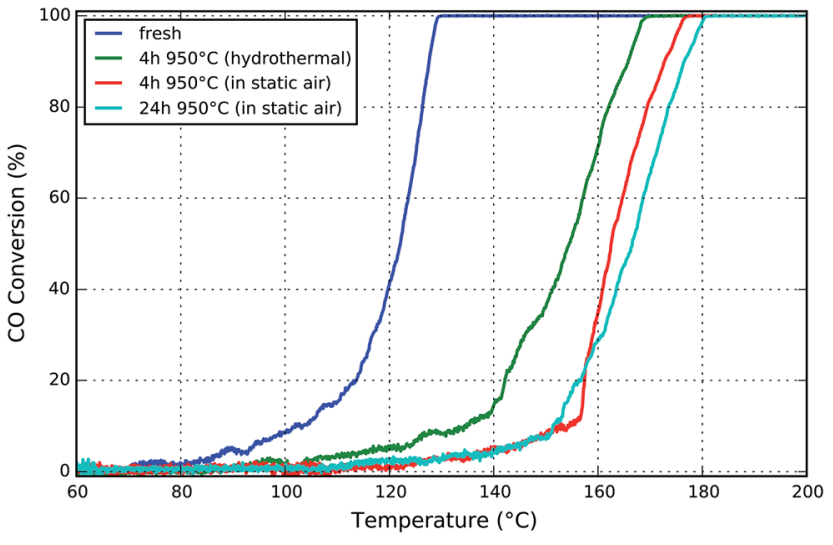

Fig. 1 Light-off curves for $\mathrm{CO}$ oxidation for honeycomb samples aged either (i) in static air for 4 and 24 hours, or (ii) with 10 vol\% $\mathrm{H}_{2} \mathrm{O}$ in the gas stream for 4 hours.

(hydrothermal) was observed. This is in line with recent catalytic and modeling studies by Chan et al. ${ }^{42}$ Although the catalyst deactivates under both aging conditions, the effect of aging in static air is significantly stronger for the given parameters and catalyst. This is maybe due to the different surface energy and wettability of the $\mathrm{Pt} / \mathrm{PtO}_{x}$ particles on the $\mathrm{Al}_{2} \mathrm{O}_{3}$ surface resulting from the interaction with the wet or dry atmosphere and Oswald ripening due to mobile $\mathrm{PtO}_{x}$ species, as found by in situ electron microscopy. ${ }^{\mathbf{1 4 - 1 6}}$ Besides the presence of chlorine traces from the hexachloroplatinic acid precursor and of water at the same time could result in possible partial redispersion of Pt via hydroxychloride platinate in addition to oxychloride platinate species. ${ }^{46,47}$ However, a more systematic study at such extreme aging temperatures would be needed to conclude on these hypotheses, since the influence of water during sintering and especially redispersion of noble metal is still controversially discussed. ${ }^{47,48}$

The increase to a six times longer aging time of $24 \mathrm{~h}$ in static air affects the catalytic activity just slightly, as evident by a small shift to about $165{ }^{\circ} \mathrm{C}$ light-off temperature. This is in line with the two reported regimes of the sintering processes for such high Pt loadings. A very steep loss of the noble metal surface occurs in the first hours of aging at temperatures above $700{ }^{\circ} \mathrm{C}$ in oxidizing atmospheres, which is followed by a slow almost linear increase of the Pt particle size..$^{\mathbf{4 2 , 4 9 , 5 0}}$ Similar observations were made for the BET surface area ( $c f$. ESI, Fig. S3†). Furthermore, the increase of the turnover rate for $\mathrm{CO}$ oxidation over larger Pt particles will compensate the decrease of the total number of active sites. ${ }^{33}$ As previously demonstrated, ${ }^{42,51}$ this is caused by the different $\mathrm{CO}$ adsorption and desorption kinetics and adsorbate-adsorbate interactions as a function of morphology and particle size distribution. Moreover, the agglomeration of $\mathrm{Pt}$, observed by $\mu$-CT ( $c f$. Section 5), may additionally compensate the loss of active sites, since increases activity can be expected..$^{52}$ On the other hand, at high temperatures deactivation may not only be due to sintering of the very small Pt particles but also due to changes in the catalytically active porous washcoat layer, which is an additional focus of this study. In this regard, a general enhancement of the thermal stability may be achieved either by addition of dopants which improve the stability of the alumina carrier or by modifications influencing the noble metal-support interaction which result in reduction of the noble metal sintering rate. ${ }^{45}$ In addition, sintering of metal particles can be prevented by application of synthesis routes that result in high initial dispersion and uniform distribution of the metal particles. This is part of ongoing research. ${ }^{45,53}$

\subsection{XRD of fresh and aged $\mathrm{Pt} / \mathrm{Al}_{2} \mathrm{O}_{3}$}

Further evidence for changes in the sample due to thermal treatment in a static air at $950{ }^{\circ} \mathrm{C}$ for 4 and 24 hours is found by recording X-ray diffraction patterns of the uncoated $\mathrm{Pt} / \gamma-\mathrm{Al}_{2} \mathrm{O}_{3}$ catalyst powders as presented in Fig. 2 . In the fresh sample no characteristic reflections of metallic Pt, e.g. at $2 \theta=81^{\circ}$, are detected due to the high dispersion. Already after 4 hours of aging at $950{ }^{\circ} \mathrm{C}$ four very intense reflections at 39, 46, 63, and $81^{\circ}$ become visible, which correspond to the (111), (200), (220), and (311) diffraction planes of metallic fcc platinum (labeled by $\diamond)$. This finding is in line with earlier studies under oxidizing conditions. ${ }^{54}$

Further aging up to $24 \mathrm{~h}$ results in narrower and more intense reflections, indicating continuation of crystallite growth due to sintering. Peak fitting allows estimating the average Pt crystallite size by using the Scherrer formula. Results are given in Table 1 . The average size increases from $24 \mathrm{~nm}$ after $4 \mathrm{~h}$ by $12.5 \%$ to $30 \mathrm{~nm}$ after $24 \mathrm{~h}$ aging at $950{ }^{\circ} \mathrm{C}$. Although this average growth rate must be much smaller as compared to initial fresh to 4 hours rate, the effect is still present and correlates with the observed slightly deteriorated catalytic activity obtained after extended aging periods. ${ }^{\mathbf{4 2 , 4 9 , 5 0}}$

The support material, $\gamma-\mathrm{Al}_{2} \mathrm{O}_{3}$, was found to be responsible for all reflections present in the fresh sample. ${ }^{55}$ Aging likewise affects the support, thus we find $\theta-\mathrm{Al}_{2} \mathrm{O}_{3}$ (marked by $\boldsymbol{\Delta}$ ) as well as some weaker contributions of $\alpha-\mathrm{Al}_{2} \mathrm{O}_{3}$ (indicated by $\left.\boldsymbol{\nabla}\right)^{56}$ for the aged samples. Hence, the question arises to which extent the phase transformation as well as the macro-porosity and possible cracks in the coated catalyst layer in addition to the sintering of $\mathrm{Pt}$ particles have an impact on the catalyst performance.

\subsection{Electron microscopy of fresh and aged $\mathrm{Pt} / \mathrm{Al}_{2} \mathrm{O}_{3}$}

The fresh sample was studied by TEM to detect highly dispersed platinum nanoparticles supported on $\gamma-\mathrm{Al}_{2} \mathrm{O}_{3}$ as shown in Fig. 3(a). The analysis of several high resolution images revealed a particle size distribution with the majority of particles below 2 $\mathrm{nm}$ in size. After finishing the last aging for $24 \mathrm{~h}$ at $950^{\circ} \mathrm{C}$ and a subsequent tomography scan, the sample was studied by SEM. The surface of the aged washcoat, still attached to the honeycomb wall, is presented in Fig. 3(b). The two images directly show the sintering of initially small well dispersed Pt particles into very large, micrometer-sized plate-like platinum single crystals, as detected by XRD. Nevertheless, still numerous small particles are observed with sizes in agreement with the results obtained by XRD. 


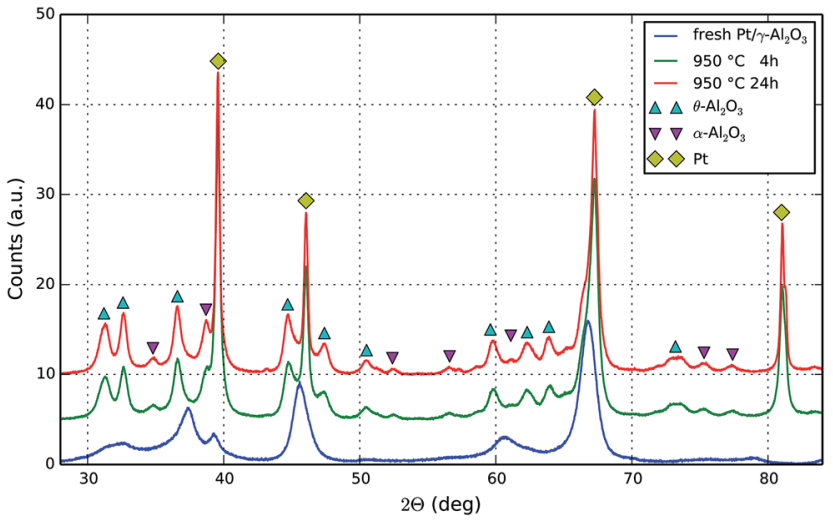

Fig. 2 Diffraction patterns of $4 \mathrm{wt} \% \mathrm{Pt} / \gamma-\mathrm{Al}_{2} \mathrm{O}_{3}$ powder: (a) fresh, (b) aged at $950^{\circ} \mathrm{C}$ in static air for $4 \mathrm{~h}$, and (c) aged for $24 \mathrm{~h}$ under the same conditions. Markers are added for metallic fcc phase of Pt $(\diamond), \theta-\mathrm{Al}_{2} \mathrm{O}_{3}$ $(\boldsymbol{\Delta})$, and $\alpha-\mathrm{Al}_{2} \mathrm{O}_{3}(\boldsymbol{\nabla})$ while $\gamma-\mathrm{Al}_{2} \mathrm{O}_{3}$ is the only detected phase in (a). The plots are unscaled and stacked for comparison.

\subsection{Honeycomb cross sections studied by EPMA and $\mu$-CT}

Scanning electron microscopy provides highly resolved images of the exterior sample surface, as shown previously, but naturally fails to image internal surfaces or sub-surface regions except further slicing (e.g. by FIB, polishing, crushing). As we are interested in the entire honeycomb channel, including cordierite walls and the full washcoat layer inside and outside the channel, we have embedded the channel (studied by tomography) after the last performed aging step of $24 \mathrm{~h}$ at $950{ }^{\circ} \mathrm{C}$ to prepare a mechanical cross section as shown in Fig. 4(a). The focus of these investigations was the washcoat interior with respect to structure and Pt distribution after aging.

Imaging has been achieved using a high resolution electron probe micro analyzer in combination with wavelengthdispersive X-ray spectroscopy (WDX) for mapping the chemical composition of the cross section. The complete honeycomb cross section, as shown in Fig. 4(a), is imaged at $40 \times$ magnification $(2.33 \mu \mathrm{m}$ per $\mathrm{px})$. At this length scale, the porous cordierite structure and the distribution of washcoat in this cross section are visible. At the same resolution, using a close up of Fig. 4(a) given in (c) pores and some bright features are observed in the washcoat.

A complementary slice of the same region taken from the beforehand conducted $\mu$-CT experiment, Fig. $4(\mathrm{~b})$, is presented to compare features and image contrast. Comparison of Fig. 4(b)

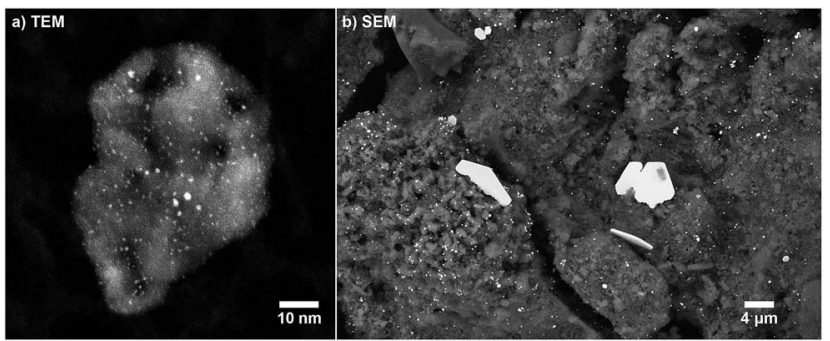

Fig. 3 (a) TEM image (STEM, 910k $\times$ magnification) of a fresh $\mathrm{Pt} / \mathrm{Al}_{2} \mathrm{O}_{3}$ sample. (b) SEM image (BSE, $8 \mathrm{k} \times$ magnification) of a sample aged for $24 \mathrm{~h}$ at $950^{\circ} \mathrm{C}$.

and (c) reveals very similar image contrast and characteristic sample features, e.g. the cordierite structure, voids and bright features within the washcoat layer. Notably, some grains with internal structure (bright rim, dark core) are found, indicating variation of Pt loading. Additionally, $\mu$-CT gives a full series of slices, similar to Fig. 4(a), of the entire channel in fresh and aged state provided as movie in the ESI (Fig. S1 and Movie $1 \dagger$ ).

High resolution EPMA $(2000 \times$ magnification, $47 \mathrm{~nm}$ per $\mathrm{px})$ which has been performed on the marked region in Fig. 4(c), resulted in the image in Fig. 4(d). It provides a detailed view on the cordierite wall (upper image area, with const. brightness) and the $\mathrm{Pt} / \mathrm{Al}_{2} \mathrm{O}_{3}$ washcoat layer (lower image area) in the sample. The aged washcoat is discontinuous with cracks and numerous voids of different sizes and shapes, providing high porosity. Moreover, the washcoat grains are heterogeneous in size, compactness, and Pt distribution, which is convoluted in the pixel brightness and is partially disentangled later by using WDX.

In Fig. 4(d), again, distinctive micrometer-sized Pt single crystals are observed within the washcoat volume. This is in direct agreement with the previous SEM image, taken from the washcoat surface (Fig. 3(a)). In fact, Fig. 4(d) provides even more insight, since we may deduce that these crystals are preferentially found in sample areas close to voids and cordierite pores providing sufficient space for growth. As shown before, a lot of small Pt particles can be found distributed all over the washcoat in accordance to XRD.

The Pt loading and distribution is resolved in detail by the WDX mapping shown as overlay in Fig. 4(e). Platinum is found to be confined to the washcoat layer, i.e. no Pt was detected in the bulk cordierite, which would potentially further deactivate

Table 1 XRD results for metallic fcc platinum

\begin{tabular}{|c|c|c|c|c|c|}
\hline Peak Pos. $(2 \Theta)$ & Diffraction plane $(h k l)$ & \multicolumn{2}{|l|}{$4 \mathrm{~h}$ @ $950{ }^{\circ} \mathrm{C}$} & \multicolumn{2}{|l|}{$24 \mathrm{~h}$ (a) $950{ }^{\circ} \mathrm{C}$} \\
\hline 46.05 & 200 & 6.63 & 22 & 5.15 & 29 \\
\hline 67.27 & 220 & 9.00 & 19 & 7.70 & 22 \\
\hline 81.06 & 311 & 6.18 & 30 & 4.45 & 41 \\
\hline
\end{tabular}




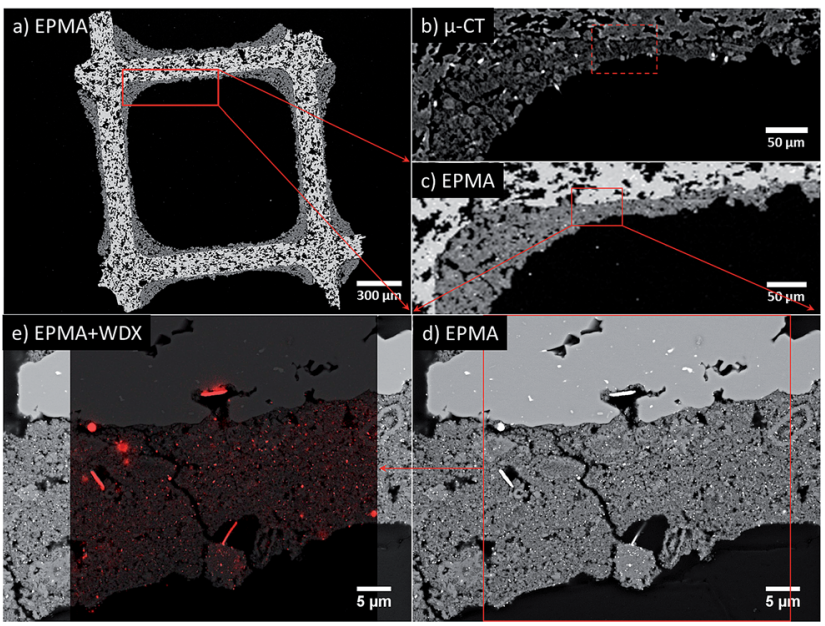

Fig. 4 Mechanical cross section of an embedded sample, aged $24 \mathrm{~h}$ at $950{ }^{\circ} \mathrm{C}$ in static air, imaged by EPMA and $\mu-\mathrm{CT}$. Back-scattered electron images of (a) the complete embedded honeycomb channel and (c) close up to the part containing the ROI box for the (d) high resolution EPMA with additional (e) WDX map of Pt overlaid. For comparison a (b) $\mu$-CT slice of the same sample part before embedding is shown with a dashed box indicating the ROI measured in ( $d$ and e).

the catalyst. Furthermore, Pt is identified as the origin of the bright features visible in the washcoat by comparison of Fig. 4(d) with the Pt mapping in Fig. 4(e). Other bright features in the bulk cordierite visible in EPMA are clearly not related to presence of Pt. Most important, these results also apply to bright spots present in the $\mu$-CT data. This becomes, evident by comparing the dashed box in Fig. 4(b), revealing high Pt loadings, with high resolution EPMA images and WDX mapping shown in Fig. 4(d) and (e).

\section{Quasi in situ tomography}

In order to acquire the honeycomb sample at the same location after subsequent sample treatments, we probed the sample volume non-destructively by X-ray absorption micro-computed tomography. This quasi in situ approach enables us to elucidate structural modifications on a micrometer scale. Here a single cordierite honeycomb channel, coated with a $4 \mathrm{wt} \% \mathrm{Pt} / \gamma^{-}$ $\mathrm{Al}_{2} \mathrm{O}_{3}$ catalyst, was sequentially aged at $950{ }^{\circ} \mathrm{C}$ in static air for 4 , 8,12 , and 24 hours and was inspected by tomography accordingly. After pre-processing the tomographic data sets, as described in Section 3.3, a voxel-by-voxel analysis is possible. To avoid confusion of with features discussed in tomography with features observed with higher resolution methods like EPMA, we introduce the phrase blobs to refer to bright, highly absorbing voxels containing sintered platinum.

This section is structured as follows: inspection of 2D slices similar to SEM, sample histogram changes as key to segmentation of sintered Pt, quantitative analysis of the sintering in average and for individual blobs, and finally a direct visualization of sintering on a piece of washcoat.

\subsection{Sequential treatments followed by virtual tomography cross sections}

From the obtained tomograms a series of virtual cross sections through the sample is compiled in Fig. 5, showing the same sample region after each treatment step. Example tomograms of the full honeycomb channel before and after aging are given in the (ESI Movies 1 and $2 \dagger$ ).

In Fig. 5 the appearance of highly absorbing (bright) blobs, as function of aging time, can be easily followed including their growth in size and number. The spot appearance shows no spatial preferences in the washcoat, i.e. homogeneous distribution. Largest spots are formed in previously empty pores (arrows in Fig. 5) or on the surface (not shown). This substantiates the results obtained from EPMA, shown in Fig. 4, by confirming the observations in the entire sample volume inspected by micro tomography. Therefore, the bright spots emerging in the washcoat can be attributed to sintered Pt agglomerates, as deduced from the EPMA results above. Nevertheless, the observed bright spots in tomography must not be exclusively attributed to the formation of large single crystals, since the obtained gray value is the average absorption over a fairly large volume as compared to EPMA pixels. This average accounts for the total amount of Pt inside the voxel, which could be a single piece, several small ones, or even a mix. Thus, no information on the number or the shape of nanoparticles inside a single micro-meter-sized voxel can be given, nevertheless the relative total Pt amount deduced from the measured voxel absorption. Further information and dedicated examples can be found in the next Section 5.2.

Cracks are present after the first treatment and change slightly in each step. Nevertheless, one can conclude that not only the cordierite ceramics but also the washcoat layer is very stable. Thus the porous layer remains rather intact. Effects of the starting phase transformations of alumina at $950{ }^{\circ} \mathrm{C}$, detected by XRD, from $\gamma$ - to small amounts of $\alpha$ - and $\theta-\mathrm{Al}_{2} \mathrm{O}_{3}$ phases do not influence the macrostructure observed by absorption contrast tomography.

In summary, rough eyeballing of the slices gives a first impression of the ongoing sintering process and demonstrates general feasibility of the measurement approach used. We are thus able to relate local properties (available space, prior homogeneity/loading etc.) to sintering behavior. In addition, the evolution of sample regions can be followed.

\subsection{CT voxel intensities compared to SEM images}

A note on the interpretation of voxel gray values is given to prevent misleading conclusions. As large Pt single crystals are detected in SEM and bright features in tomographic slices so far, tone may be tempted to assume that the latter correspond to just one single crystal, too, which is not necessarily always true. An example is given in Fig. 6 to clarify this issue. The SEM image (BSE, $10 \mathrm{k} \times$ mag.) shows several features marked by boxes on a grid which indicates the voxel size of $1.27 \mu \mathrm{m}$ obtained in tomography. Based on the SEM image a pixelated "low resolution" image is calculated simulating the corresponding average gray value (absorption) using the given voxel size. 


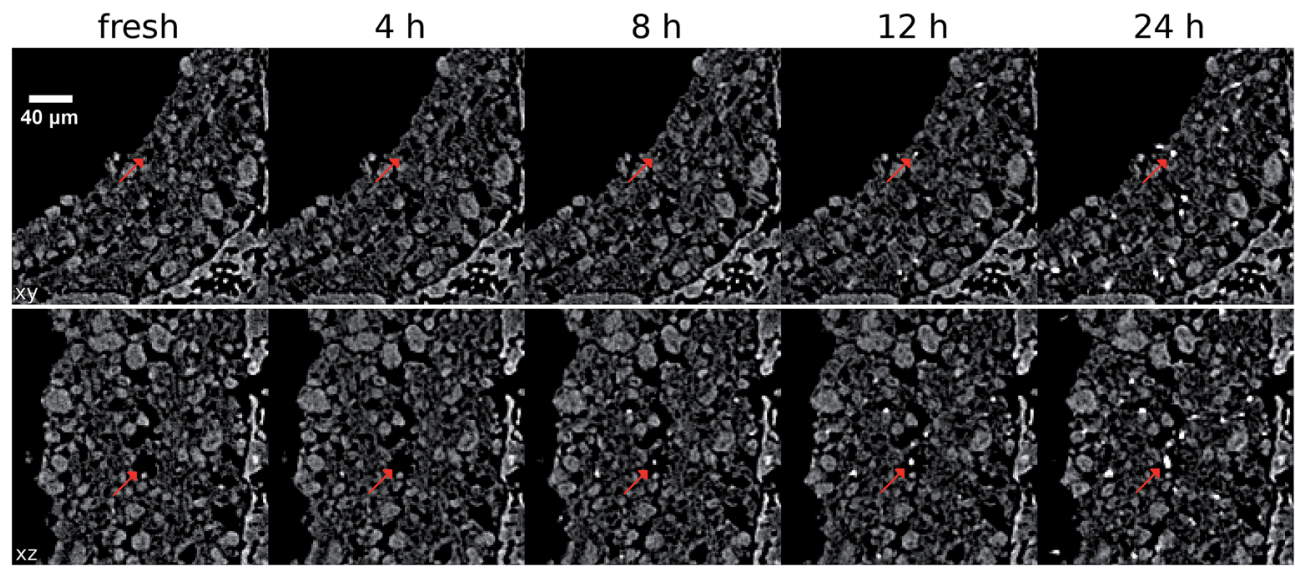

Fig. 5 Virtual cross sections through tomographic reconstructions for each aging step at $950^{\circ} \mathrm{C}$. Views are presented for planes along $x y$ and $x z$. The magnification, $40 \mu \mathrm{m}$ scale bar, and gray scale are identical for all slices. Arrows indicate sintered features.

As evident from the SEM image in Fig. 6 Pt single crystals can fully, partially or cumulatively contribute to the total voxel absorptions as indicated by the colored boxes. Voxels with a different number of Pt crystals inside but with a very similar total amount of Pt (blue box) have the same average absorption. Hence, we cannot distinguish whether one of them is composed of just one large single crystal or several small crystals. Volume averaging in combination with a very structured support (voids, inhomogeneous Pt loading etc.) may even cause $\mu \mathrm{m}$ sized crystals (green box) to disappear completely. Similarly, a $\mu \mathrm{m}$-sized crystal (magenta box) may become hard to distinguish from

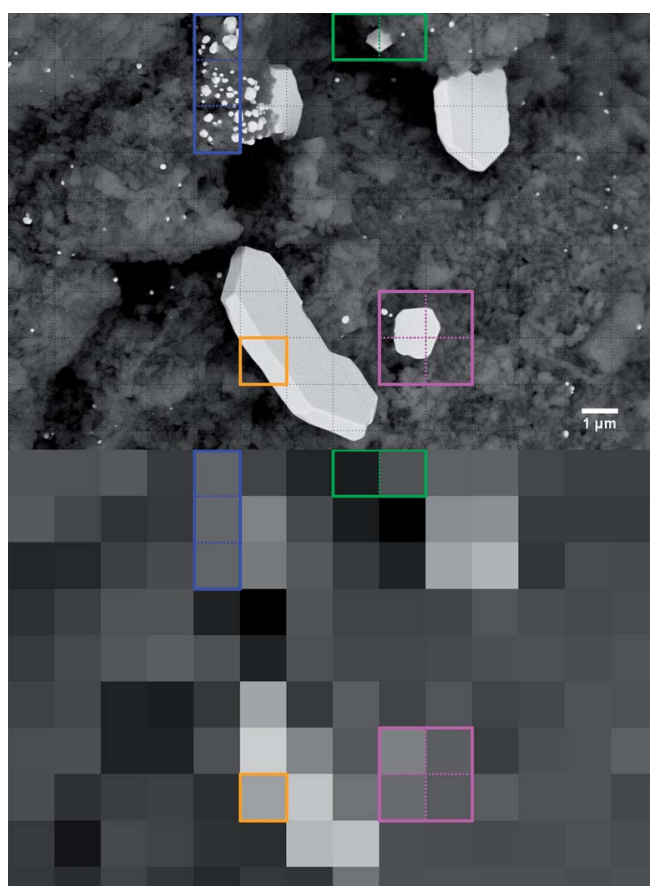

Fig. 6 Comparison of pixel and voxel sizes in SEM and $\mu-C T$ images relevant for data interpretation. (a) SEM image of a $\mathrm{Pt} / \mathrm{Al}_{2} \mathrm{O}_{3}$ sample (aged $24 \mathrm{~h}$ (a $950{ }^{\circ} \mathrm{C}$ ) reveals various large platinum crystals. (b) Simulating the effect of $1.27 \mu \mathrm{m} \mu$-CT voxel size by box averaging of (a). the average substrate due to unfavorable sampling into several voxels. Even the large plate like crystal might not completely fill a 3D voxel (orange box) because of insufficient thickness, which results in lowered absorption although the voxel is part of a huge crystal. Altogether this complicates especially the correlation of gray value and platinum loading. Nevertheless, X-ray absorption micro-computed tomography allows the observation of overall and $\mu \mathrm{m}$-resolved dynamics for catalyst coated cordierite cores which occur due to sintering and redistribution of the components.

\subsection{Blob extraction by histogram segmentation}

In order to analyze the observed blobs in Fig. 5 in more detail, they first need to be separated from the tomographic sample volume. This is achieved using the characteristic modifications evident in the histograms for the aged sample shown in Fig. 7 and by performing a volume segmentation based on a threshold gray value.

In the histograms, shown in Fig. 7, hardly any difference between the fresh and the $4 \mathrm{~h}$ aged sample is observed, which is also due to the limited resolution. The first considerable deviation from the initial state is found after $8 \mathrm{~h}$ aging, which is further enhanced with increasing aging duration. The number of voxels assigned to high gray values increases simultaneously with the highest obtained gray value as a function of aging time. This is attributed to sintered platinum in combination with increased local Pt concentration due to Pt migration, which is in line with direct observations made in the slices presented in Fig. 5.

The emerging highly absorbing voxels are used to perform a segmentation based on thresholding into sintered and nonsintered washcoat parts. A gray value threshold of $3.00 \times 10^{-3}$ was set, based upon the mean washcoat gray value of $(1.15 \pm$ $0.52) \times 10^{-3}$, which is approximately three times the mean value or six times the standard deviation and thus allows reliable segmentation. To keep the visualization simple, we analyzed a single corner with dimensions $800 \times 300 \times 300 \mu \mathrm{m}$, 


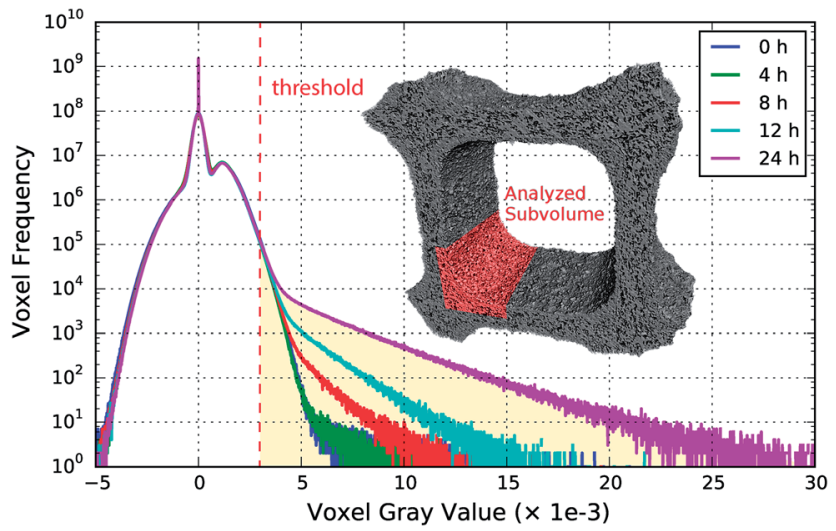

Fig. 7 Histograms of the tomographic data for each aging step at $950{ }^{\circ} \mathrm{C}$ in static air. Deviations at high gray values indicate emergence of sintered platinum and its aggregation in individual voxels in the shaded region with absorption above the threshold value. Rendering of the full tomographic volume, used for the histograms, and highlighted sample corner for later analysis.

extracted from the full tomogram, as shown in Fig. 7. This approach can be analogously extended to the complete volume.

\subsection{Segmentation and analysis of a honeycomb channel corner}

The described segmentation has been performed using Avizo Fire $^{37}$ and yields the sintered platinum blobs from the raw tomographic data, shown in blue in Fig. 8. This sintered part is further split up into separated unconnected regions, shown as colored objects in Fig. 8, which embody the already mentioned blobs. Each colored blob is assigned to an individual label, which allows referencing and inspecting them separately. By completing this last step, integral and individual analysis can be performed as presented in the following.

\subsection{Progress of blob formation}

The progress of the blob formation can be followed across all sequential treatment steps, as is presented in the following image sequence in Fig. 9. The bulk (non-sintered) washcoat has
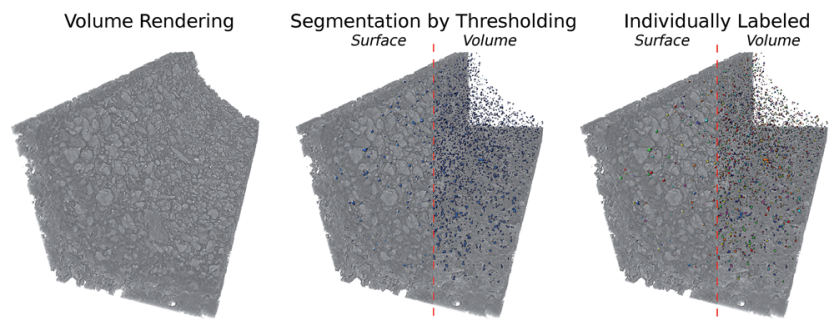

Fig. 8 Volume renderings of the analyzed honeycomb channel aged for $12 \mathrm{~h}$ at $950{ }^{\circ} \mathrm{C}$. The segmentation yields all sintered voxels (blue) with high absorption, i.e. high Pt concentration, identical to bright regions in the left image. These are further separated into individually labeled blobs, indicated by different colors. Results of the last two steps are presented as view on surface and entire volume. been removed to reveal sub surface blobs, as reference structure the cordierite wall is drawn. The analysis of individual blobs is presented in the following section. High resolution images are provided in the (ESI: Fig. S1†).

Fig. 9 allows a direct qualitative view on the sintering progress across the entire washcoat volume. A steady increase in number and size of blobs is observed, which is in line with observation by EPMA (Fig. 4) and the changes observed by comparison of X-ray tomographic images (Fig. 5), which underlines the homogeneous distribution of blobs in the sample.

\subsection{Quantitative analysis of sintering effects}

For each aging step, the ensemble of blobs, shown in Fig. 9, was quantitatively analyzed in terms of the total number of blobs, occupied washcoat volume fraction, as well as ensemble averaged mean blob absorption (gray value) and mean blob volume, which is presented in Fig. 10.

The total number of blobs (Fig. 10, red) in the fresh and $4 \mathrm{~h}$ aged sample is quite similar. Further aging steps, 4 to 8 and 8 to 12 hours, induce a rapid increase in the total number with constant slope. Hence, a sintering seems to be a continuously on-going process at $950{ }^{\circ} \mathrm{C}$. The last aging step of 12 to $24 \mathrm{~h}$ still shows more blobs, but with a decreasing rate. This shows that we have not yet reached the final state but seems to slow down the formation of new blobs after long aging durations, eventually in favor of increasing already existing blobs.

The platinum concentration per voxel is encoded in the mean gray value (Fig. 10, blue). Already after the first treatment of $4 \mathrm{~h}$ we clearly see a raised value, followed by a steady growth. Starting from $8 \mathrm{~h}$ aging an almost linear increase of the average voxel absorption over aging time is observed. This implies continuous accumulation of additional platinum into the blob voxels. Simultaneously, the initial slight drop in the total number (red) is in coincidence with a slight increase in absorption. This could indicate a densification of the initially present blobs and could be due to the redistribution of $\mathrm{Pt}$ particles, i.e. smaller Pt particles disappear and integrate into the larger ones.

Considering the average blob volume (Fig. 10, orange), found per aging step, we observe a non-linear growth with increasing rate towards extended aging times. As the mean blob volume (orange) and the mean blob absorption (blue) increase together, a very pronounced transfer of platinum from other non-blob voxels into those blobs occurs. Consequently, rather large amounts of platinum agglomerate and show up as sintered particles, in agreement with results from SEM/EPMA. Hence, there is profound evidence for platinum redistribution and accumulation (mass transfer) into the marked blobs that takes place on the micrometer scale. Similar to this trend the total occupied volume of all blobs (Fig. 10, green), as a fraction of the total washcoat volume, is increasing from initially almost zero to finally reach $1.1 \mathrm{vol} \%$. This demonstrates that the evolution from a fresh washcoat, with homogeneously distributed Pt, towards an aged catalyst layer, with locally varying Pt concentration, can be followed on the micrometer scale using characteristic measures. 


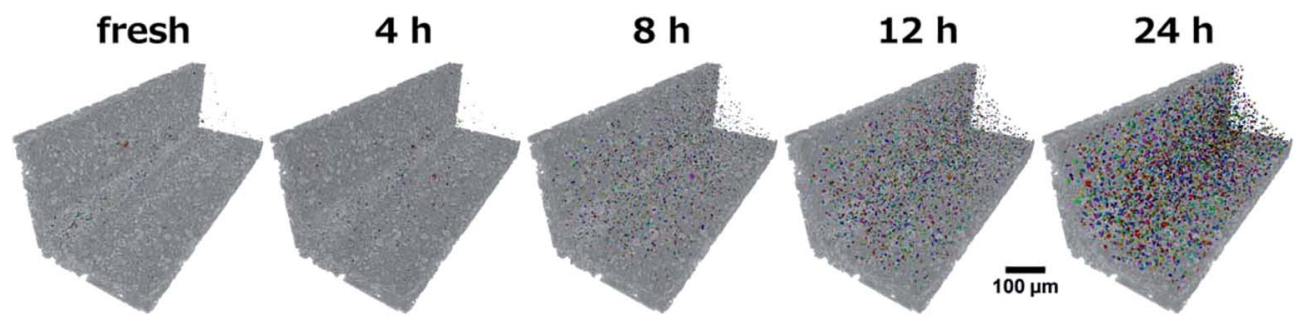

Fig. 9 Evolution of the blob ensemble with increasing aging time in the sample corner (gray).

\subsection{Correlation of blob volume and Pt loading}

The observed simultaneous growth of mean blob absorption and mean blob volume is further examined, but instead of considering ensemble averages every individual blob is accounted using a $2 \mathrm{D}$ representation of blob volume against gray value. Note that the blob gray value is still averaged, since in general a single blob is composed of several voxels with varying absorption. In Fig. 11 both quantities, individual blob volume and blob absorption, are plotted. The frequency of
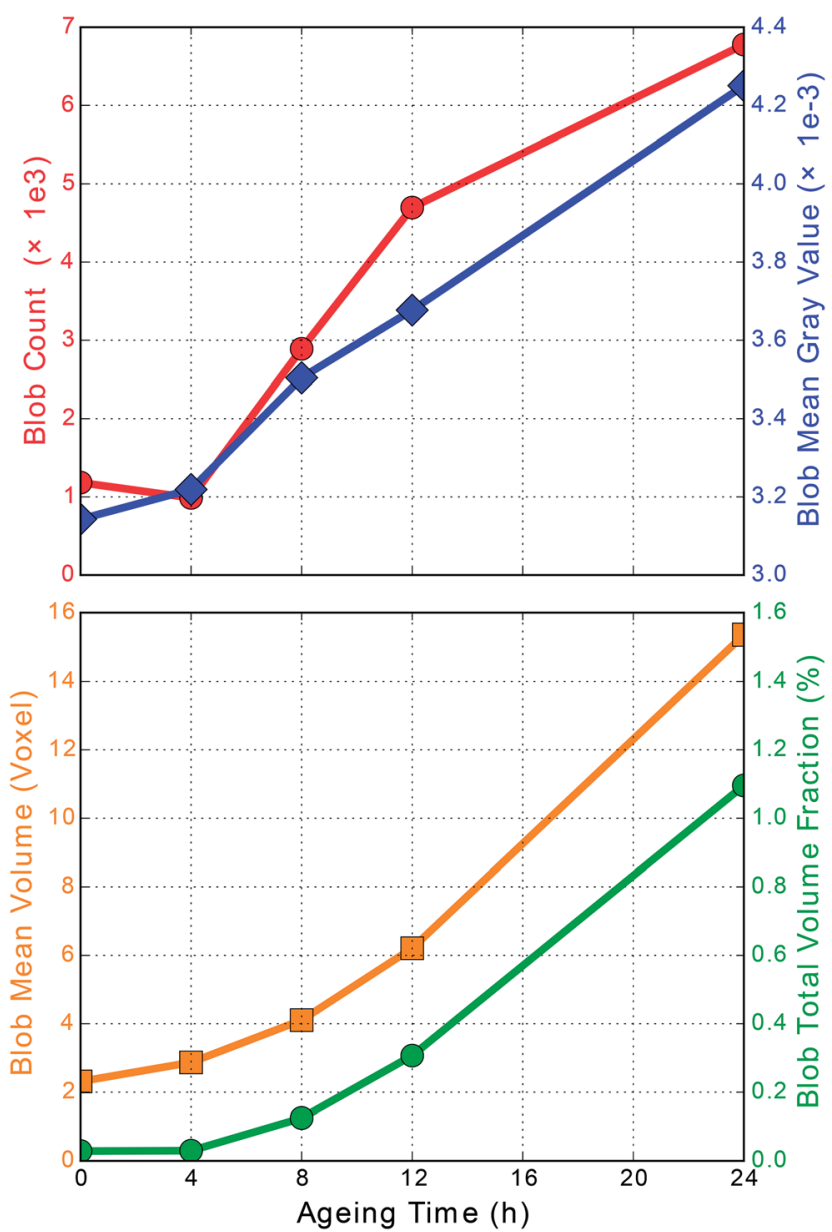

Fig. 10 Evolution of the blob ensemble over aging time characterized by the total blob number (red), average blob gray value (blue), average blob volume (orange), and resulting occupied washcoat volume fraction (green). blobs meeting a certain combination of gray value and volume is denoted by colors using a logarithmic scale.

By using 2D histograms for every treatment step, we obtain a valuable perspective on the growth characteristics. Especially the spread of the blob gray values and volumes can be seen. The tight correlation is confirmed by the plots showing systematic growth with little scattering. Most blobs are located in and emerge from the lower left corner, i.e. with an initially small volume and low absorption. As aging proceeds, blobs first fan out mostly towards higher absorption (increasing Pt concentration) and later on also towards larger volumes. This seems to indicate underlying Ostwald ripening, where first a critical mass/size is required before extensive size growth takes places. Most highly absorbing blobs with very high volumes are found after $24 \mathrm{~h}$ aging, although a few can be found in earlier stages.

\subsection{View on the washcoat}

Prior analysis revealed in general the emergence of initially small blobs with increased platinum content, which will grow as aging proceeds. Hence, a washcoat subvolume was visualized to monitor and demonstrate the effects observed in Sections 5.6 and 5.7 in a spatially resolved manner. In Fig. 12 a series of colored volume renderings is presented, which allows us to follow changes in absorption and grain shape directly. The color range is chosen to reflect characteristic properties of the washcoat, which was already used for the segmentation (see Fig. 11). Essentially, it spans from the mean washcoat gray value $\left(1.0 \times 10^{-3}\right.$, dark blue partially transparent $)$ to the threshold value $\left(3.0 \times 10^{-3}\right.$, orange $)$ with both limits additionally extended by $1 \sigma\left(0.5 \times 10^{-3}\right)$. Moreover, an animated volume rendering as function of aging time is given as movie in the (ESI: Fig. S2 and Movie $3 \dagger$ ).

In Fig. 12 we observe a quite homogeneous fresh state (greenish). Already after $4 \mathrm{~h}$ aging first spots (orange) show up. More areas with high absorption and thus high Pt loading (red) have formed after $8 \mathrm{~h}$ and continue to extend and intensify as evident in the 12 and $24 \mathrm{~h}$ renderings. Simultaneously with formation of Pt agglomerates, depicted in red, decreasing Pt concentration is observed in the surrounding voxels, evident by color changes from greenish to light and dark/transparent blue. This gives indirect proof of the sintering process, where some regions continuously grow into bigger "particles" as they "consume" Pt from nearby resources.

The redistribution of $\mathrm{Pt}$ is visible on single alumina support grains, but more pronounced between different grains, i.e. in an 


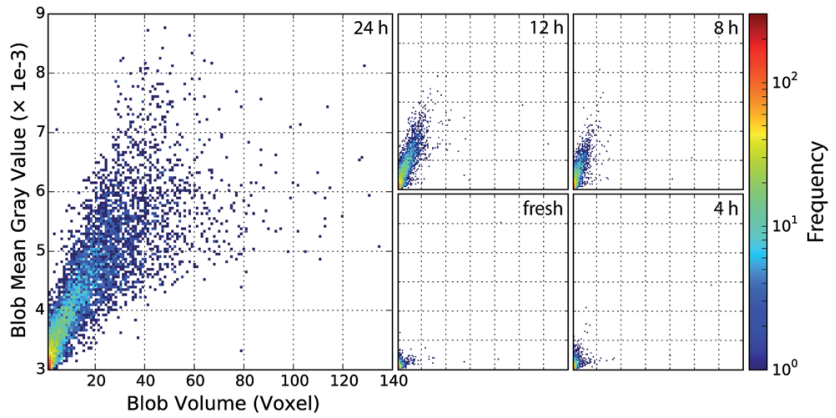

Fig. $112 \mathrm{D}$ histograms of blob mean gray values and volumes confirming the correlation of the plotted quantities. The main frame shows the state after $24 \mathrm{~h}$ aging at $950^{\circ} \mathrm{C}$ and prior steps in the small frames. Frequencies are displayed using a logarithmic scale, see color bar.

intra and inter grain fashion. This explains the local decrease in absorption at some positions, while at the same time the X-ray absorption significantly increases elsewhere. This suggests diffusion of Pt-species on the grains of the alumina particles, in agreement with earlier observations. ${ }^{\mathbf{1 4 , 1 6}}$

\section{Discussion of the aging of $\mathrm{Pt}$ particles}

The results show that the aging of $\mathrm{Pt} / \mathrm{Al}_{2} \mathrm{O}_{3}$, which leads to decreased CO-conversion, can be traced back to changes on the nano and the microscale. In agreement, with earlier studies, which have not only been performed ex situ but even in situ using ETEM, ${ }^{\mathbf{6} 14}$ strong sintering is typically observed above $750{ }^{\circ} \mathrm{C}$. This strongly affects the catalytic performance due to a strong decease in the number of surface sites, in agreement with recent modeling studies. ${ }^{12,42}$ At $950{ }^{\circ} \mathrm{C}$, which was the focus of this work, still small Pt-particles apart from larger ones can be found (Fig. 3), but quasi in situ X-ray absorption microcomputed tomography ( $\mu$-CT) shows that during aging sintering occurs at $950{ }^{\circ} \mathrm{C}$ continuously as function of time. Although the particle size cannot be derived directly from $\mu$-CT data due to its comparably large voxel size, the evolution of strongly absorbing voxels as visible in the complete histogram (Fig. 7); and the formation of bigger, strongly absorbing Pt-rich regions (blobs) are observed (Fig. 10). EPMA has been used as in previous studies as a very powerful analytical method to sensitively determine the elemental distribution with high lateral resolution. This was also beneficial for the interpretation of $\mu$ -
CT data. However, only a single mechanical cross section is usually studied by EPMA and high resolution images, especially mappings are very time consuming which practically limits the amount of sample which can be investigated. Furthermore, the sample is partially destroyed by preparation of mechanical cross-sections and remaining parts are typically sealed in epoxy resin. Therefore, no EPMA images of the same sample can be taken before and after treatments and most other investigations are impossible. One could alternatively study different samples after several stages of treatment. However, this would require an impractical high number of multiple samples to be studied in order to obtain sufficient statistics for uncovering changes on the micrometer scale which are not related to the preparation process and it is highly advantageous to use a combination of EPMA and $\mu$-CT for such studies. ${ }^{57}$ This allows exploiting the strengths of tomography, namely the preservation of the sample, the larger sample volume, giving much better statistics than 2D-sections in SEM (Fig. 3), and the access to the inner volume of the sample.

Whereas, on a nanometer scale a detailed insight into the particle sintering has been achieved recently, ${ }^{\mathbf{6}, 14}$ the sintering at elevated temperatures and on a micrometer scale has hardly been studied. The present study, which allowed investigating the catalyst channel at exactly the same position after the corresponding treatment, shows that the cordierite, the alumina carrier, and washcoat have a good stability on the micrometer scale. In the washcoat, the absorption coefficient and hence the Pt-content of a few grains strongly increases with time. Once these regions have formed after 8 hours aging time, their absorption coefficient and size further increase after 12 and 24 hours (Fig. 11). These findings support the presence of sintering based on Oswald ripening, which leads to the growth of large particles in voids between support grains of the washcoat layer. No diffusion into the cordierite has been detected neither by EPMA analysis nor $\mu$-CT. This mechanism was also concluded from bimodal particle size distributions in studies on the nanometer scale. ${ }^{\mathbf{1 4 - 1 6}}$ Hence, also on this sub- $\mu \mathrm{m}$ to $\mu \mathrm{m}$ scale this mechanism is valid and catalyst deactivation is not due to changes in porosity of the washcoat layer which would also lead to a significant change in the mass and heat transport properties. $^{58}$

The evident Pt redistribution and resulting Pt concentration variation of the catalyst has significant influence on the catalytic performance as we have seen in Section 4.1 with CO oxidation. This is also an important non-constant parameter for modeling

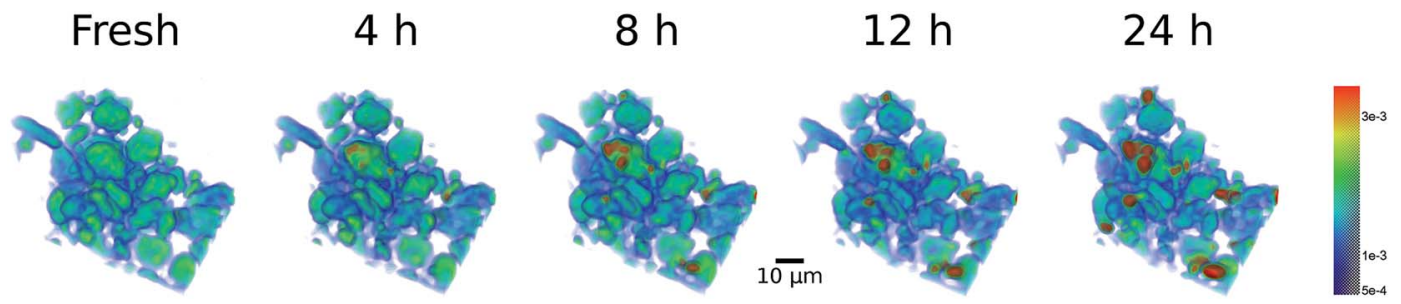

Fig. 12 Washcoat volume rendering illustrating the impact of aging time at $950^{\circ} \mathrm{C}$ in static air. 
these systems, e.g. cracks and cavities enhancing diffusion ${ }^{21}$ and higher activity of bigger Pt agglomerates. ${ }^{52}$

Although CO oxidation activity, XRD, and BET data show significant changes after the first aging step, they yield rather small changes upon extending the aging duration from $4 \mathrm{~h}$ to 24 h. This is in contrast to complementary $\mu$-CT. Nevertheless XRD and $\mathrm{CO}$ oxidation are techniques sensitive to the Pt structure on the nanometer scale, but are of sample averaging manner. Therefore local outliners might not be represented very well until they become the majority and are still equally well detected. A local investigation using SEM/TEM is able to identify such changes, as well as $\mu$-CT clearly reveals changes in the sample locally resolved. For obtaining direct correlation between the observed $\mu$-CT blobs and the CO oxidation or XRD data, supplementary activity and characterization measurements need to be conducted on samples very similar to the probed voxels. Considering aging and sintering gradients along a sample, which might be identified by $\mu$-CT, suitable samples could be obtained for such specific/targeted experiments aiming at obtaining information for direct correlation.

Apart from information on the Pt distribution, the tomographic data, as given in Fig. 12, is also a decisive digital input for multiscale modeling studies. Usually pore structures for such modeling are extracted from indirect methods like mercury porosimetry or three-dimensional information is generated by time consuming FIB-SEM experiments. ${ }^{21,59} \mu-\mathrm{CT}$ can provide this information directly and without the need of elaborate sample preparation. In principle such information can also be received with much higher resolution using X-ray tomography. ${ }^{60}$ Compared to FIB-SEM and EPMA, that can also provide local information up to the $\mu \mathrm{m}$-scale, $\mu$-CT and related $\mathrm{X}$-ray tomographic techniques have the advantage that they are non-destructive and therefore quasi-in situ or, in future, even operando studies can be performed. In situ sample environments are a routine tool at synchrotron radiation tomography beamlines and the high flux makes operando studies of aging effects possible and feasible. Appropriate reaction cells allow to perform the reaction under different atmospheric conditions. This seems particularly important during ageing studies since the reaction atmosphere strongly influences the sintering behavior (Fig. 1 and ref. 19 and 61). In addition, apart from simple absorption contrast also element and structure sensitivity can be exploited using XAS, ${ }^{62} \mathrm{XRF}^{63}{ }^{63} \mathrm{XR}^{29}$ and $\mathrm{SAXS}^{64}$ computed tomography, which is complementary to fast developments for lab CT instruments including e.g. hyperspectral Xray radiography. ${ }^{65}$

\section{Conclusion}

The study shows that quasi in situ X-ray absorption microcomputed tomography is an important complementary tool to follow and unravel the changes of exhaust gas catalysts during aging at elevated temperatures. Most important benefits arise from non-destructive preparation and investigation enabling consecutive studies of the same sample and from sampling larger volumes to ensure representative results or even detect favored locations and gradients along the sample. This is of great interest for many kinds of catalytic systems like particles in fluidized beds, shell-impregnated catalysts or materials like batteries, fuel cells or sensors and complements studies performed by EPMA analysis combined with FIB.

In order to monitor the changes in a washcoat layer during aging, we have shown here that analysis of the same sample volume using special analysis tools is beneficial. This comprises alignment of all samples to the same location, analysis of the evolution of the blob ensemble with high Pt-content (or strong X-ray absorption), histograms of absorption strength and comparison of regions of interest. In principle, the development of suitable sample holders and the refinement of tomography approaches will allow investigation of catalyst samples at relevant temperatures and realistic gas atmospheres in situ and even operando using this technique.

With the quasi in situ approach presented here, combined with SEM and EPMA, XRD and catalytic studies, we found the sintering of initially small well dispersed Pt particles into very large, micrometer-sized plate-like platinum single crystals. The sintering process at $950{ }^{\circ} \mathrm{C}$ is an on-going process as proven by $\mu$-CT, a result that was not visible by use of other techniques (e.g. hardly detected by XRD). The correlation plots of blob formation indicate a growth process according to Oswald ripening.

More information can be gained from tomography experiments by exploitation of other contrasts than absorption, e.g. fluorescence and/or diffraction. These can reveal, for example, the phase transformation of the $\gamma-\mathrm{Al}_{2} \mathrm{O}_{3}$ support, evident from $\mathrm{XRD}$, which was not captured here in pure absorption mode. With the development of advanced laboratory CT setups, $\mu$-CT will very likely grow into a custom method for material and catalyst analysis, and also allow (quasi) in situ studies at medium resolution.

\section{Acknowledgements}

We thank the virtual institute VI-403 "In situ Nano-Imaging of Biological and Chemical Processes", the BMBF-projects "X-ray microscopy" (05K10VK1) and "Nanoscopy" (05K13VK2) for financial support, Di Wang (KNMF, KIT) for TEM measurements, Uta Gerhards (IMVT, KIT) for EPMA sample preparation and investigation and Volker Zibat (LEM, KIT) for coating and SEM imaging of honeycomb channels. Furthermore, we are grateful for beamtime at PETRA III. A. Rochet and G. Hofmann additionally thank the Alexander von Humboldt Foundation and the Helmholtz Research School "Energy-Related Catalysis" for grants, respectively. M. Ogurreck gratefully acknowledges financial support from the German Research Foundation (DFG, via SFB $986 \mathrm{M}^{3}$, project $\mathrm{Z} 2$ ).

\section{References}

1 R. M. Heck, R. J. Farrauto and S. T. Gulati, Catalytic air pollution control. Commercial technology, John Wiley, Hoboken, N.J, 3rd edn, 2009. 
2 M. Votsmeier, T. Kreuzer, J. Gieshoff and G. Lepperhoff, Automobile Exhaust Control. Ullmann's Encyclopedia of Industrial Chemistry, 2009.

3 M. V. Twigg, Catal. Today, 2011, 163, 33-41.

4 O. Deutschmann and J.-D. Grunwaldt, Chem. Ing. Tech., 2013, 85, 595-617.

5 D. Ferri, M. A. Newton, M. Di Michiel, S. Yoon, G. L. Chiarello, V. Marchionni, S. K. Matam, M. H. Aguirre, A. Weidenkaff, F. Wen and J. Gieshoff, Phys. Chem. Chem. Phys., 2013, 15, 8629-8639.

6 T. W. Hansen, A. T. DeLaRiva, S. R. Challa and A. K. Datye, Acc. Chem. Res., 2013, 46, 1720-1730.

7 K. A. Christensen, in Chemical Product Design. Towards a Perspective through Case Studies, ed. K. M. Ng, R. Gani and K. Dam-Johansen, Elsevier, Burlington, 2006, p. 311.

8 J.-D. Grunwaldt, J. B. Wagner and R. E. Dunin-Borkowski, ChemCatChem, 2013, 5, 62-80.

9 J. L. Williams, Catal. Today, 2001, 69, 3-9.

10 O. Deutschmann, Modeling and simulation of heterogeneous catalytic reactions. From the molecular process to the technical system, John Wiley \& Sons; Wiley-VCH, Weinheim, 2013.

11 (a) J. Andersson, M. Antonsson, L. Eurenius, E. Olsson and M. Skoglundh, Appl. Catal., B, 2007, 72, 71-81; (b) D. M. Fernandes, C. F. Scofield, A. A. Neto, M. J. B. Cardoso and F. M. Z. Zotin, Process Saf. Environ. Prot., 2009, 87, 315-322.

12 K. Hauff, U. Tuttlies, G. Eigenberger and U. Nieken, Appl. Catal., B, 2010, 100, 10-18.

13 (a) A. D. Benavidez, L. Kovarik, A. Genc, N. Agrawal, E. M. Larsson, T. W. Hansen, A. M. Karim and A. K. Datye, ACS Catal., 2012, 2, 2349-2356; (b) T. W. Hansen and J. B. Wagner, ACS Catal., 2014, 4, 1673-1685.

14 A. T. DelaRiva, T. W. Hansen, S. R. Challa and A. K. Datye, J. Catal., 2013, 308, 291-305.

15 S. B. Simonsen, I. Chorkendorff, S. Dahl, M. Skoglundh, J. Sehested and S. Helveg, J. Am. Chem. Soc., 2010, 132, 7968-7975.

16 S. B. Simonsen, I. Chorkendorff, S. Dahl, M. Skoglundh, K. Meinander, T. N. Jensen, J. V. Lauritsen and S. Helveg, J. Phys. Chem. C, 2012, 116, 5646-5653.

17 R. Ouyang, J.-X. Liu and W.-X. Li, J. Am. Chem. Soc., 2013, 135, 1760-1771.

18 (a) M. H. Wiebenga, C. H. Kim, S. J. Schmieg, S. H. Oh, D. B. Brown, D. H. Kim, J.-H. Lee and C. H. Peden, Catal. Today, 2012, 184, 197-204; (b) A. Winkler, D. Ferri and M. Aguirre, Appl. Catal., B, 2009, 93, 177-184.

19 S. K. Matam, E. V. Kondratenko, M. H. Aguirre, P. Hug, D. Rentsch, A. Winkler, A. Weidenkaff and D. Ferri, Appl. Catal., B, 2013, 129, 214-224.

20 P. Kočí, F. Štěpánek, M. Kubíček and M. Marek, Chem. Eng. Sci., 2006, 61, 3240-3249.

21 V. Novák, P. Kočí, T. Gregor, J.-S. Choi, F. Štěpánek and M. Marek, Catal. Today, 2013, 216, 142-149.

22 (a) V. Meille, Appl. Catal., A, 2006, 315, 1-17; (b) C. Agrafiotis and A. Tsetsekou, J. Eur. Ceram. Soc., 2000, 20, 815-824; (c)
P. Jiang, G. Lu, Y. Guo, Y. Guo, S. Zhang and X. Wang, Surf. Coat. Technol., 2005, 190, 314-320.

23 B. M. Weckhuysen, Angew. Chem., Int. Ed., 2009, 48, 49104943.

24 (a) B. M. Weckhuysen, Phys. Chem. Chem. Phys., 2003, 5, 4351-4360; (b) J.-D. Grunwaldt and A. Baiker, Phys. Chem. Chem. Phys., 2005, 7, 3526-3539; (c) J.-D. Grunwaldt and B. S. Clausen, Top. Catal., 2002, 18, 37-43; (d) S. Zhang, L. Nguyen, Y. Zhu, S. Zhan, C.-K. Tsung and F. Tao, Acc. Chem. Res., 2013, 46, 1731-1739.

25 P. Echlin, Handbook of sample preparation for scanning electron microscopy and X-ray microanalysis, Springer, New York, London, 2009.

26 (a) S. R. Stock, Int. Mater. Rev., 1999, 44, 141-164; (b) S. R. Stock, Int. Mater. Rev., 2008, 53, 129-181.

27 G. Hofmann, A. Rochet, S. Baier, M. Casapu, S. Ritter, F. Wilde, M. Ogurreck, F. Beckmann and J.-D. Grunwaldt, J. Phys.: Conf. Ser., 2014, 499, 012017.

28 D. Bernard, D. Gendron, J.-M. Heintz, S. Bordère and J. Etourneau, Acta Mater., 2005, 53, 121-128.

29 F. Basile, P. Benito, S. Bugani, W. de Nolf, G. Fornasari, K. Janssens, L. Morselli, E. Scavetta, D. Tonelli and A. Vaccari, Adv. Funct. Mater., 2010, 20, 4117-4126.

30 F. Tariq, R. Haswell, P. D. Lee and D. W. McComb, Acta Mater., 2011, 59, 2109-2120.

31 A. P. Cocco, G. J. Nelson, W. M. Harris, A. Nakajo, T. D. Myles, A. M. Kiss, J. J. Lombardo and W. K. S. Chiu, Phys. Chem. Chem. Phys., 2013, 15, 16377-16407.

32 E. Maire and P. J. Withers, Int. Mater. Rev., 2014, 59, 1-43.

33 A. Boubnov, A. Gänzler, S. Conrad, M. Casapu and J.-D. Grunwaldt, Top. Catal., 2013, 56, 333-338.

34 (a) A. C. Kak and M. Slaney, Principles of Computerized Tomographic Imaging, IEEE Press, 2001; (b) T. M. Buzug, Computed tomography. From Photon Statistics to Modern Cone-Beam CT, Springer, Berlin, Heidelberg, 2008; (c) G. T. Herman, Fundamentals of Computerized Tomography. Image Reconstruction from Projections, Springer, London, 2nd edn, 2009.

35 J.-Y. Buffiere, E. Maire, J. Adrien, J.-P. Masse and E. Boller, Exp. Mech., 2010, 50, 289-305.

36 (a) A. Haibel, M. Ogurreck, F. Beckmann, T. Dose, F. Wilde, J. Herzen, M. Müller, A. Schreyer, V. Nazmov, M. Simon, A. Last and J. Mohr, Micro- and nano-tomography at the GKSS Imaging Beamline at PETRA III, Proc. SPIE, 2010, 7804, 78040B, DOI: 10.1117/12.860852; (b) A. Haibel, F. Beckmann, T. Dose, J. Herzen, M. Ogurreck, M. Müller and A. Schreyer, Powder Diffr., 2010, 25, 161-164; (c) I. Greving, F. Wilde, M. Ogurreck, J. Herzen, J. U. Hammel, A. Hipp, F. Friedrich, L. Lottermoser, T. Dose, H. Burmester, M. Müller and F. Beckmann, P05 imaging beamline at PETRA III: first results, Proc. SPIE, 2014, 9212, 92120O, DOI: 10.1117/12.2061768.

37 VSG|FEI Visualization Sciences Group, Avizo Fire 8.1.

38 T. E. Oliphant, Comput. Sci. Eng., 2007, 9, 10-20.

39 J. D. Hunter, Comput. Sci. Eng., 2007, 9, 90-95.

40 J. Schindelin, I. Arganda-Carreras, E. Frise, V. Kaynig, M. Longair, T. Pietzsch, S. Preibisch, C. Rueden, 
S. Saalfeld, B. Schmid, J.-Y. Tinevez, D. J. White, V. Hartenstein, K. Eliceiri, P. Tomancak and A. Cardona, Nat. Methods, 2012, 9, 676-682.

41 P. Scherrer, Göttinger Nachrichten Math. Phys., 1918, vol. 2, pp. 98-100.

42 D. Chan, S. Tischer, J. Heck, C. Diehm and O. Deutschmann, Appl. Catal., B, 2014, 156-157, 153-165.

43 X. Chen, Y. Cheng, C. Y. Seo, J. W. Schwank and R. W. McCabe, Appl. Catal., B, 2015, 163, 499-509.

44 J. Yang, V. Tschamber, D. Habermacher, F. Garin and P. Gilot, Appl. Catal., B, 2008, 83, 229-239.

45 A. Russell and W. S. Epling, Catal. Rev.: Sci. Eng., 2011, 53, 337-423.

46 (a) J. Barbier, D. Bahloul and P. Marecot, Catal. Lett., 1991, 8, 327-333; (b) H. Lieske, G. Lietz, H. Spindler and J. Völter, J. Catal., 1983, 81, 8-16.

47 F. Le Normand, A. Borgna, T. F. Garetto, C. R. Apesteguia and B. Moraweck, J. Phys. Chem., 1996, 100, 9068-9076.

48 T. J. Lee and Y. G. Kim, J. Catal., 1984, 90, 279-291.

49 P. Forzatti and L. Lietti, Catal. Today, 1999, 52, 165-181.

50 C. H. Bartholomew, in Studies in Surface Science and Catalysis: Catalyst Deactivation 1994 Proceedings of the 6th International Symposium, ed. B. Delmon and G. F. Froment, Elsevier, 1994, vol. 88, pp. 1-18.

51 E. I. Altman and R. J. Gorte, Surf. Sci., 1988, 195, 392-402.

52 K. Arnby, A. Törncrona, B. Andersson and M. Skoglundh, J. Catal., 2004, 221, 252-261.

53 (a) A. Papavasiliou, A. Tsetsekou, V. Matsouka, M. Konsolakis and I. V. Yentekakis, Appl. Catal., A, 2010, 382, 73-84; (b) A. Papavasiliou, A. Tsetsekou, V. Matsouka, M. Konsolakis, I. V. Yentekakis and N. Boukos, Appl. Catal., B, 2009, 90, 162-174; (c) A. Papavasiliou, A. Tsetsekou, V. Matsouka, M. Konsolakis, I. V. Yentekakis and N. Boukos, Appl. Catal., B, 2011, 106, 228-241; (d) R. U. Ribeiro, D. M. Meira, C. B. Rodella, D. C. Oliveira, J. M. C. Bueno and D. Zanchet, Appl. Catal., A, 2014, 485, 108-117.
54 G. W. Graham, H.-W. Jen, W. Chun, H. P. Sun, X. Q. Pan and R. W. McCabe, Catal. Lett., 2004, 93, 129-134.

55 Y. Liu, D. Ma, X. Han, X. Bao, W. Frandsen, D. Wang and D. Su, Mater. Lett., 2008, 62, 1297-1301.

56 Y. Saito, T. Takei, S. Hayashi, A. Yasumori and K. Okada, J. Am. Ceram. Soc., 1998, 81, 2197-2200.

57 Q. Hu, L. M. Tyler, J. Davis, J. C. Hanan, R. Frazier and Y. Zhang, Fuel, 2014, 116, 229-236.

58 L. L. Raja, R. J. Kee, O. Deutschmann, J. Warnatz and L. D. Schmidt, Catal. Today, 2000, 59, 47-60.

59 (a) P. Kočí, V. Novák, F. Štěpánek, M. Marek and M. Kubíček, Chem. Eng. Sci., 2010, 65, 412-419; (b) T. Nien, J. P. Mmbaga, R. E. Hayes and M. Votsmeier, Chem. Eng. Sci., 2013, 93, 362375; (c) V. Malavé, J. R. Berger, H. Zhu and R. J. Kee, Electrochim. Acta, 2014, 130, 707-717.

60 D. Müter, H. O. Sørensen, D. Jha, R. Harti, K. N. Dalby, H. Suhonen, R. Feidenhans'l, F. Engstrøm and S. L. S. Stipp, Appl. Phys. Lett., 2014, 105, 043108.

61 X. Auvray, T. Pingel, E. Olsson and L. Olsson, Appl. Catal., B, 2013, 129, 517-527.

62 C. G. Schroer, M. Kuhlmann, T. F. Gunzler, B. Lengeler, M. Richwin, B. Griesebock, D. Lutzenkirchen-Hecht, R. Frahm, E. Ziegler, A. Mashayekhi, D. R. Haeffner, J.-D. Grunwaldt and A. Baiker, Appl. Phys. Lett., 2003, 82, 3360-3362.

63 (a) L. Vincze, B. Vekemans, F. E. Brenker, G. Falkenberg, K. Rickers, A. Somogyi, M. Kersten and F. Adams, Anal. Chem., 2004, 76, 6786-6791; (b) L. Vincze, B. Vekemans, I. Szaloki, F. E. Brenker, G. Falkenberg, K. Rickers, K. Aerts, R. van Grieken, F. Adams and U. Bonse, Proc. SPIE, 2004, 5535, 220-231.

64 (a) T. H. Jensen, M. Bech, O. Bunk, A. Menzel, A. Bouchet, G. Le Duc, R. Feidenhans'l and F. Pfeiffer, NeuroImage, 2011, 57, 124-129; (b) C. G. Schroer, M. Kuhlmann, S. V. Roth, R. Gehrke, N. Stribeck, A. AlmendarezCamarillo and B. Lengeler, Appl. Phys. Lett., 2006, 88, 164102.

65 S. D. M. Jacques, C. K. Egan, M. D. Wilson, M. C. Veale, P. Seller and R. J. Cernik, Analyst, 2013, 138, 755-759. 